\title{
Erratum to: Evaluating Mendelian nephrotic syndrome genes for evidence for risk alleles or oligogenicity that explain heritability
}

Brendan D. Crawford ${ }^{1}$ - Christopher E. Gillies ${ }^{1} \cdot$ Catherine C. Robertson $^{1}$ •

Matthias Kretzler $^{2} \cdot$ Edgar A. Otto $^{2} \cdot$ Virginia Vega-Warner $^{1} \cdot$ Matthew G. Sampson $^{1}$

Published online: 27 March 2017

(C) IPNA 2017

Erratum to: Pediatric Nephrology.

DOI 10.1007/s00467-016-3513-3

Owing to oversights by the authors, the name of the author Virginia Vega-Warner was incorrectly rendered as "Vega-Wagner". In addition, Edgar A. Otto was wrongly listed as "Edgar Otto".

The authors regret these errors and apologise for the inconvenience caused.

The online version of the original article can be found at http://dx.doi. org/10.1007/s00467-016-3513-3

Matthew G. Sampson

mgsamps@med.umich.edu

1 Department of Pediatrics, University of Michigan Medical School, 3560B MSRB 2, Ann Arbor, MI, USA

2 Department of Internal Medicine, University of Michigan Medical, School, Ann Arbor, MI, USA 